\title{
Orthogonal cameras system for tracking of laparoscopic instruments in training environments
}

\author{
Sistema de cámaras ortogonales para el seguimiento de instrumentos laparoscópicos en \\ entornos de entrenamiento
}

\begin{abstract}
Fernando Pérez-Escamirosa1*, Ignacio Oropesa², Patricia Sánchez-González²,3, Jesús Tapia-Jurado Jorge Ruiz-Lizarraga ${ }^{4}$ and Arturo Minor-Martínez ${ }^{5}$

${ }^{1}$ Department of Surgery, Faculty of Medicine, Universidad Nacional Autónoma de México (UNAM), Ciudad de México, Mexico; ${ }^{2}$ Biomedical Engineering and Telemedicine Centre (GBT), ETSI Telecomunicación, Center for Biomedical Technology, Universidad Politécnica de Madrid (UPM), Madrid, Spain; ${ }^{3}$ Biomedical Research Networking Centre in Bioengineering, Biomaterials and Nanomedicine (CIBER-BBN), Madrid, Spain; ${ }^{4}$ Centro de Enseñanza por Simulación de Posgrado (CESIP), Unidad de Posgrado, Universidad Nacional Autónoma de México, Facultad de Medicina, Universidad Nacional Autónoma de México Ciudad de México, Mexico; ${ }^{5}$ Department of Electrical Engineering, Bioelectronics Section, Centro de Investigación y de Estudios Avanzados del Instituto Politécnico Nacional (CINVESTAV-IPN), Ciudad de México, Mexico
\end{abstract}

\begin{abstract}
Introduction: Motion analysis is a valuable tool for assessment of psychomotor skills in laparoscopy. Nonetheless, it requires technologies for tracking the activity of the laparoscopic instruments during training. This paper presents a sensor-free system to track the movements of laparoscopic instruments based on an orthogonal camera system and video image processing. Methods: The movements of the laparoscopic instruments are tracked with two webcams placed in an orthogonal configuration. The position and orientation in the three-dimensional workspace are obtained using color markers placed on the tip of the instruments. Results: Accuracy tests show a resolution of $0.14 \mathrm{~mm}$ for displacement, with $1694 \mathrm{~cm}^{3}$ of total workspace, and $0.54^{\circ}$ in the angular movements. Mean relative errors of the tracking system were $<1 \%$. The orthogonal cameras show high precision, linearity, and repeatability of motion recording of the laparoscopic instruments. Conclusion: The proposed system offers unconstrained manipulation of the instruments and a low-cost alternative for traditional tracking technologies.
\end{abstract}

KEY WORDS: Laparoscopy. Video-based tracking system. Orthogonal cameras. Triangulation. Motion analysis.

\section{Resumen}

Introducción: El análisis del movimiento es una valiosa herramienta para la evaluación de las habilidades psicomotrices en la laparoscopia. Sin embargo, requiere tecnologías para el seguimiento de la actividad de los instrumentos laparoscópicos durante el entrenamiento. En este artículo presentamos una técnica sin sensores para realizar el seguimiento de los movimientos de los instrumentos laparoscópicos basado en un sistema de cámara ortogonal y procesamiento de imágenes de video. Método: Los movimientos de los instrumentos laparoscópicos son capturados con dos cámaras web colocadas en configuración ortogonal. La posición y la orientación en el espacio de trabajo tridimensional se obtienen utilizando marcadores de color colocados en la punta de los instrumentos. Resultados: Las pruebas de precisión mostraron una resolución de $0.14 \mathrm{~mm}$ para el desplazamiento, con $1694 \mathrm{~cm}^{3}$ de espacio de trabajo total y $0.54^{\circ}$ en los movimientos angulares. Los errores relativos medios del sistema de seguimiento fueron $<1 \%$. Las cámaras ortogonales demostraron alta precisión, linealidad y repetibilidad de la captura de movimiento de los instrumentos laparoscópicos. Conclusiones: El sistema propuesto ofrece

\author{
Correspondence: \\ *Fernando Pérez-Escamirosa, \\ Department of Surgery, UNAM, Circuito Interior \\ Av. Universidad, 3000 \\ Ciudad Universitaria, Del. Coyoacán \\ C.P. 04510, Ciudad de México, México \\ E-mail: ferescamirosa@unam.mx
}

Date of reception: 09-04-2018

Date of acceptance: 11-05-2018

DOI: 10.24875/CIRU.18000348

Cir Cir. 2018;86:548-555

Contents available at PubMed

www.cirugiaycirujanos.com 
una manipulación sin restricciones de los instrumentos laparoscópicos y una alternativa de bajo costo para las tecnologías tradicionales de captura de movimiento.

PALABRAS CLAVE: Laparoscopia. Sistema de seguimiento en video. Cámaras ortogonales. Triangulación. Análisis de movimiento.

\section{Introduction}

Laparoscopic surgery is a minimally invasive approach which is performed through small incisions in the patient's abdominal wall. Through these small incisions, special long surgical instruments are introduced into the abdominal cavity by means of cannulas (trocars). The workspace within the abdominal cavity is obtained with the pneumoperitoneum generated by insufflated $\mathrm{CO}_{2}$ gas. Visualization of the internal anatomy is obtained by an endoscopic camera, which shows a two-dimensional (2D) image on an external monitor'.

Over the past few decades, laparoscopic surgery has become a standard procedural in many surgical interventions. This surgical technique has many important benefits for the patient such as less pain and organ damage, shorter recovery and hospitalization periods, better cosmetic outcomes, and earlier returns to regular activities ${ }^{2}$. However, laparoscopy involves significant technical challenges different from those in conventional open surgery. Laparoscopic surgery requires high skill and dexterity in the use of long surgical instruments that reduce haptic sensation, as well as adaptation to a limited workspace and the loss of depth information due to indirect visualization of $2 \mathrm{D}$ endoscopic images ${ }^{3}$.

Surgeon's training is the centerpiece of safe and successful laparoscopic surgery ${ }^{4-7}$; therefore, it is important to develop training systems that allow the development and improvement of the surgeon's skills as well as the measurement and assessment of the level obtained. The use of training systems such as physical trainers ${ }^{8-10}$, virtual (VR), and augmented reality (AR) simulators ${ }^{11-17}$ has proven to be reliable tools for learning and for continuous improvement of the surgeon's motor skills in patient-free environments, which may be transferable to the operating room. These systems use various technologies to measure instrument movements during training ${ }^{18-20}$. However, the majority of these devices, in particular, the VR and AR simulators, use mechanical linkages associated with the displacement of the instruments or sensors that modify and restrict the surgeon's freedom of movement altering the experience and performance.
At present, there are alternatives to capture and record the movement of the instruments by means of image analysis. These registration systems, based on computer vision techniques, offer a viable alternative for the training systems and the operating room. In the operating theater, there are systems for robotic-assisted surgery and mechatronic assisted camera holders ${ }^{21-24}$. These robotic systems use color segmentation techniques to detect the tip of the instruments with markers ${ }^{22}$, geometric models of the camera using the spatial information from the incision points, or the optics vision field combined with the shape of the long surgical instruments ${ }^{24}$. In training environments, some applications have also been developed for video-based tracking of the laparoscopic instruments. This concept is used in the ProMIS simulator (CAE Health care, Montreal, Canada) $)^{11,13,14}$, in which three separate cameras capture, in Cartesian coordinates $(x, y$, and $z$ ), the movement of laparoscopic instruments inside a mannequin. However, the elements that make up the tracking system are fixed to the ProMIS system and cannot be exported to another simulator.

Other approaches are presented by Cano et al. ${ }^{25,26}$ and Allen et al. ${ }^{27}$ in which the three-dimensional (3D) movements of the instruments are captured using the 2D image from the endoscope of a box trainer, gathering information on the instruments' position from the vision field, as well as their shape and vanishing point within the image. These systems are sensitive to illumination changes, which result in errors during the estimation of the instruments' edge (which, in turn, are based in edge detection algorithms such as Canny and Sobel filtering). Moreover, if the field of view of the endoscope is obstructed or the instruments are crossed, it will produce tracking errors.

In this article, we present the development of a tracking system of laparoscopic instruments, which uses two inexpensive cameras, instead of three cameras, in orthogonal configuration, and video image processing. The orthogonal cameras system enables capturing of the movements by triangulating the position of the tip of the laparoscopic instruments in the workspace, without relying on the estimation of the instruments' geometry. This video-based tracking 
device is portable and easy to install in any training environment and platform without making important modifications to their structure. In addition, this system allows the free manipulation of laparoscopic instruments since it does not use sensors or mechanical joints associated to them, offering a feasible alternative to traditional tracking systems.

\section{Materials and methods}

\section{Laparoscopic instruments}

Laparoscopic instruments are the principal means for manipulating organs and tissues inside the abdominal cavity of the patient. The design of these instruments consists of a long slender shaft of $5-\mathrm{mm}$ in diameter and $32-\mathrm{cm}$ in length, with jaws and teeth that allow a gentle and secure grip of tissue (Fig. 1). The instrument handle controls the opening/closing of jaws, as well as motions in four degrees of freedom (DOF) (up/down, left/right forward/backward, and tip's rotation).

\section{Tracking system description}

The video-based tracking system consists of two webcams placed on orthogonal configuration to capture the 3D motions of the laparoscopic instruments in real-world coordinates. The capture and image processing of the surgical instruments is done online. The webcams are installed in a steel sheet at a distance of $13.5 \mathrm{~cm}$ from each other, keeping an orthogonal disposition (Fig. 2A). With this feature, the image plane of the top and bottom cameras is parallel to $x-y$ and $x-z$ planes of motion of the instruments, respectively (Fig. 2B).

Software implementation is performed using the OpenCV library in $\mathrm{C}$ language. There are several phases associated with the tracking system's algorithm:

\section{Correction of IMAGES}

Distortion of the image - radial or barrel - is a recurring phenomenon which deforms the images in a nonlinear way, from the optical center toward the periphery. This distortion is caused by optical aberrations of the camera lens ${ }^{28}$. To determine and correct the images coming from the orthogonal cameras, a correction software based on the algorithms of ${ }^{28,29}$ is applied to both images.

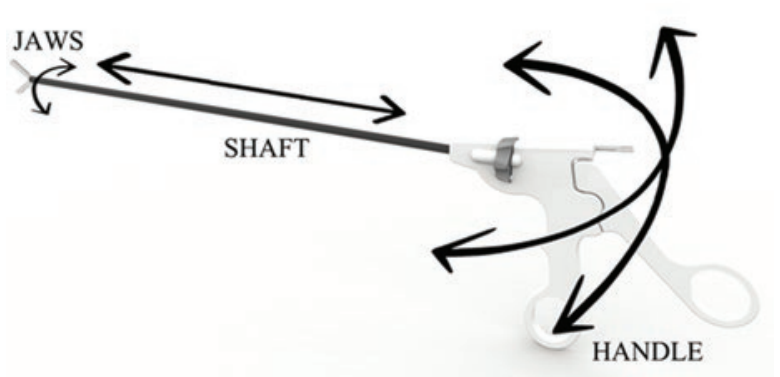

Figure 1. Degree of freedoms of laparoscopic instruments.

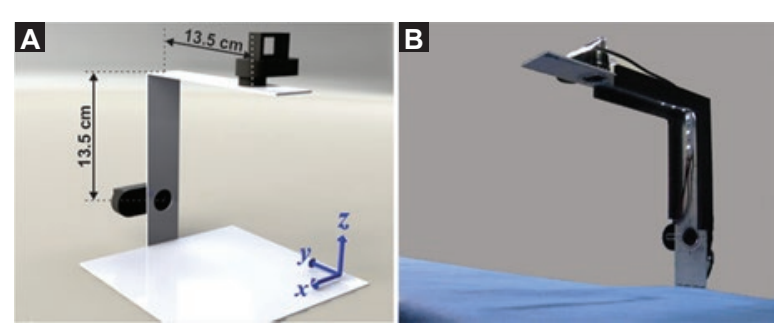

Figure 2. Video-tracking system based on two inexpensive webcams placed in orthogonal configuration. (A) Isometric representation of the orthogonal webcams at a distance of $13.5 \mathrm{~cm}$. (B) Final design of the cameras system.

\section{DETECTION OF LAPAROSCOPIC INSTRUMENTS}

To facilitate the detection of laparoscopic instruments in the image, green and blue color markers are placed near the tip of each surgical instrument. The system employs a similar color-based segmentation as described by Wei et al. ${ }^{22}$, which isolates the instrumental color markers within the image. Once the objects of interest are detected within the image, first-and second-order moments ${ }^{30}$ are calculated to determine the centroid (center of mass) of the markers in the image coordinates $(u, v)$, and the angle $(\theta)$ of the instrument with respect to the point of incision or cannulas. The noise in the segmented image, which does not belong to the object of interest, is removed by means of two opening morphological operators $^{31}$.

\section{DETERMINATION OF THE POSITION OF THE INSTRUMENTS}

To find the 3D position of laparoscopic instruments within the workspace created from the orthogonal cameras, an algorithm based on linear triangulation method was implemented ${ }^{32,33}$. This method determines the position of an object in 3D space by analyzing the intersection of two lines using two images taken 
with a cameras system and the equation system $(u=P x)$. To solve this equation, it is necessary to have 6 reference points in image coordinates $(u, v)$ with their corresponding real-world coordinates $x=(x, y, z)$ and calculate the coefficients of the $P$ projection matrix $^{34}$. This result allows us to resolve the ambiguity resulting from the placement of the orthogonal cameras.

\section{Orthogonal camera calibration}

For this process, we searched the best 6 benchmarks to get an optimal triangulation with the most accurate results (Table 1). A total of four linear equations in real-world coordinates $\mathrm{x}=(x, y, z)$ were obtained from two images. The solution for these equations in terms of real-world coordinates was obtained using the technique of single value decomposition $^{34}$. As a result of this algorithm, only the surgical instrument coordinates in the images are needed to determine the 3D location in the real-world coordinate scene. These image coordinates are introduced into the four equations, which may be written in the form $A x=0$ for a suitable $4 \times 4$ matrix, $A$, to obtain their corresponding values in real-world coordinates $x=(x, y, z)^{32}$ (Fig. 3).

Finally, $[x(t), y(t), z(t)]_{t=0}^{T}$ the motion data of the laparoscopic instruments are stored in separate sections within a text file (*.txt) for further analysis.

\section{Technical validation}

Once the software calibration for the orthogonal cameras model was developed, a series of tests were conducted to determine the linearity and repeatability of the movements registered with the orthogonal cameras system. The standard coordinate system of a universal milling machine was used as a pattern for these trials. This machine has a resolution of $25.4 \mu \mathrm{m}$ in each of its three axes and was used to precisely control the position of the tip of the instrument in the directions $x, y$, and $z$. In addition, the milling machine also allows controlled movements at different speeds. During the tests, the steel sheet with the webcams

Table 1. Reference points for calibration of the orthogonal cameras

\begin{tabular}{|c|c|c|c|}
\hline \multirow[t]{2}{*}{$\begin{array}{l}\text { Reference } \\
\text { points }\end{array}$} & $\begin{array}{l}\text { Real-world } \\
\text { coordinates }\end{array}$ & $\begin{array}{c}\text { Image } \\
\text { coordinates } \\
\text { Top } \\
\text { camera }(x-y)\end{array}$ & $\begin{array}{l}\text { Image } \\
\text { coordinates } \\
\text { Bottom } \\
\text { camera }(x-z)\end{array}$ \\
\hline & $(x, y, z)^{\mathrm{a}}$ & $(u, v)^{\mathrm{b}}$ & $(u, v)^{\mathrm{b}}$ \\
\hline 1 & $(0,0,0)$ & $(39.04,17.28)$ & $(142.44,107.81)$ \\
\hline 2 & $(10,4,0)$ & $(600.80,237.78)$ & $(509.60,73.08)$ \\
\hline 3 & $(5,8,0)$ & $(312.73,462.74)$ & $(295.22,16.70)$ \\
\hline 4 & $(0,8,4)$ & $(122.92,389.23)$ & $(15.39,239.45)$ \\
\hline 5 & $(10,8,8)$ & $(484.46,350.36)$ & $(582.20,464.87)$ \\
\hline 6 & $(5,0,8)$ & $(327.95,98.66)$ & $(305.59,368.15)$ \\
\hline
\end{tabular}

aThe coordinates are expressed in centimeters. ${ }^{\mathrm{b} T h e}$ coordinates are expressed in pixels.
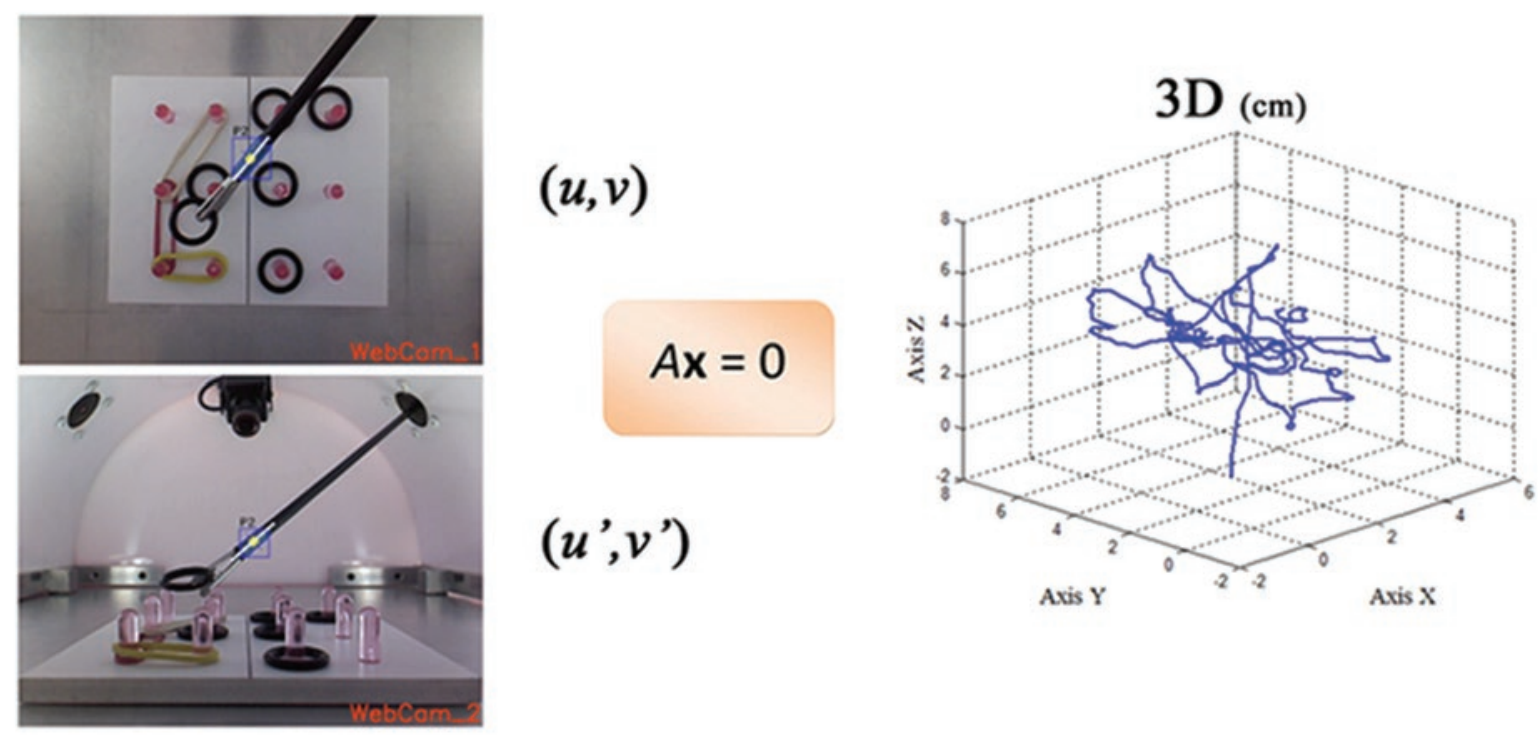

Figure 3. Determination of the three-dimensional position of surgical instrument (cm) by means of triangulation the position of the colored marker in the images (pixel). 


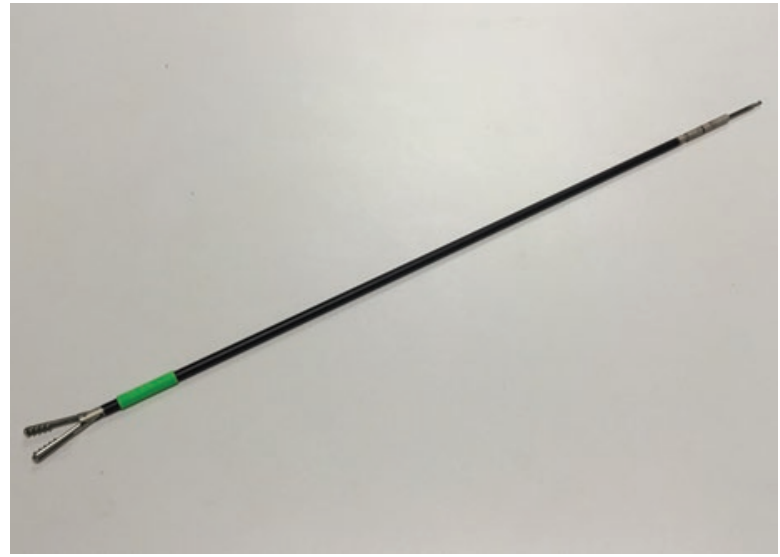

Figure 4. Laparoscopic instrument without the handle used for the validation process.

was mounted on the platform of this universal milling machine. A laparoscopic instrument with a green color marker was modified, its handle removed, to attach it to the chuck of the milling machine (Fig. 4).

With this modification, the laparoscopic instrument was placed on the chuck at an angle of $45^{\circ}$. The instrument was moved in relation to the tracking system in $60 \mathrm{~mm}$ linear motion along three DOF (3DOF: left-right, up-down, and forward-backward) and at 3 different speeds $(375,650$, and $850 \mathrm{~mm} / \mathrm{min})$. These movements were performed in two ways: moving from point $a$ to point $b(a-b)$ and moving from point $a$ to point $b$ to point $a(a-b-a)$ (Fig. 5A). These movements were recorded 30 times within the working space of the cameras. The resolution on each axis and the interpretation of possible systematic and random errors in the registers were obtained with these trials.

For evaluation of angular movements, the surgical instrument with the green marker was rotated on its point of the incision from left-right at speeds of 2, 4, and $6 \mathrm{rpm}$. The movements, point $a$-point $b(a-b)$ and point $a$-point $b$ to point $a(a-b-a)$, were made from $0^{\circ}$ to $90^{\circ}$ and were registered 30 times (Fig. 5B). The resolution of the angles in the planes $x-y, \theta_{x y}$ and $x-z, \theta_{x z}$, and the interpretation of possible errors during the registration process was obtained with these trials. For all tests, the relative error (\%) of the measurements recorded was calculated with the following equation ${ }^{20}$ :

$$
\text { Error }=\frac{x_{\text {real }}-x_{\text {measure }}}{x_{\text {real }}} \times 100
$$

Where $x_{\text {real }}$ is the distance in millimeters obtained by the milling machine and $x_{\text {measure }}$ is the distance in millimeters measured by the cameras system. The mean

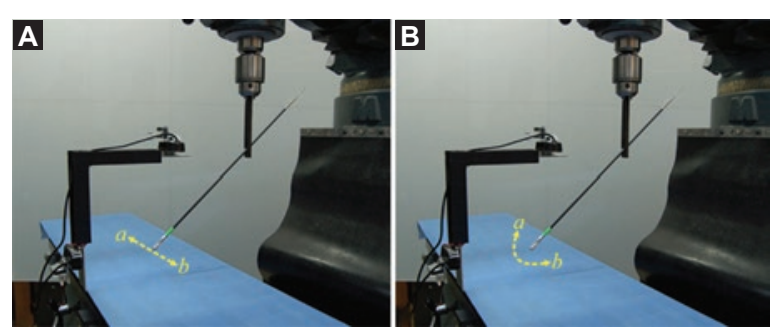

Figure 5. Placement of cameras on the platform of the milling machine with the modified surgical instrument for experimental testing. (A) Linear displacements. (B) Angular movements.

error and standard deviation were calculated for both tests.

\section{Results}

The results of all trials with the orthogonal cameras system and the calculation of the relative errors are presented in table 2 .

The results of the linear displacements showed the minimum movement that the orthogonal cameras system can track in the 3DOF allowed. The resolution of the system for the $1^{\text {st }}$ DOF (left-right) was $0.1359 \mathrm{~mm}$. For this degree of freedom, the visual system could record up to $140 \mathrm{~mm}$ of the workspace. For the $2^{\text {nd }}$ DOF (up-down), the resolution of the system was $0.1421 \mathrm{~mm}$ with a total displacement of $110 \mathrm{~mm}$ in the workspace. Finally, the resolution of the system for the $3^{\text {rd }}$ DOF (forward-backward) was $0.1451 \mathrm{~mm}$, and a total displacement of $110 \mathrm{~mm}$ movement was allowed. The results do not show any trends in the recorded motion as nonlinearities in the working axes. The total workspace of the cameras system was $1694 \mathrm{~cm}^{3}$.

The results of the angular movement of the instrument showed the minimum angle that can be observed with this tracking system. The resolution for the angle $\theta_{x y}$ was $0.5329^{\circ}(0.0093 \mathrm{rad})$ and $0.4898^{\circ}(0.0085 \mathrm{rad})$ for the angle $\theta_{x z}$. In these trials, 4 measurements were excluded from the recorded data due to outliers, according to the guidelines in Osborne et al. ${ }^{35}$ Figure 6 shows examples of the results for linear displacements $a-b$ (Fig. 6A) and $a-b-a$ (Fig. 6B), and for angular movements $a-b$ (Fig. $6 \mathrm{C}$ ) and $a-b-a$ (Fig. $6 \mathrm{D}$ ).

\section{Discussion}

The goal of this study was to present the development of an orthogonal cameras system for tracking the 3D movements of laparoscopic instruments using online video image processing. We have demonstrated the feasibility of using a vision system based on orthogonal 
Table 2. Results of testing obtained by the orthogonal cameras system

\begin{tabular}{|c|c|c|c|c|}
\hline Test & Speed & $\begin{array}{l}\text { Distance } \\
a-b\end{array}$ & $\begin{array}{c}a-b^{3} \text { Mean relative error } \pm \\
\text { SD (\%) }\end{array}$ & $\begin{array}{c}a-b-a^{4} \text { Mean relative error } \pm \\
\text { SD (\%) }\end{array}$ \\
\hline \multirow[t]{3}{*}{ (Left-rigth) $^{1}$} & 375 (mm/min) & $60 \mathrm{~mm}$ & $-0.3648 \pm 0.3866$ & $-0.3733 \pm 0.3228$ \\
\hline & $650(\mathrm{~mm} / \mathrm{min})$ & $60 \mathrm{~mm}$ & $-0.5363 \pm 0.4887$ & $-0.4578 \pm 0.5295$ \\
\hline & $850(\mathrm{~mm} / \mathrm{min})$ & $60 \mathrm{~mm}$ & $-0.4337 \pm 0.7509$ & $-0.4381 \pm 0.6703$ \\
\hline \multirow[t]{3}{*}{$(\text { up-down })^{1}$} & $375(\mathrm{~mm} / \mathrm{min})$ & $60 \mathrm{~mm}$ & $-0.3101 \pm 0.3692$ & $-0.3416 \pm 0.2965$ \\
\hline & $650(\mathrm{~mm} / \mathrm{min})$ & $60 \mathrm{~mm}$ & $-0.5491 \pm 0.5014$ & $-0.5838 \pm 0.4532$ \\
\hline & $850(\mathrm{~mm} / \mathrm{min})$ & $60 \mathrm{~mm}$ & $-0.5312 \pm 0.5763$ & $-0.5881 \pm 0.5163$ \\
\hline \multirow[t]{3}{*}{$\left(\right.$ forward-backward) ${ }^{1}$} & 375 (mm/min) & $60 \mathrm{~mm}$ & $-0.4823 \pm 0.4214$ & $-0.3376 \pm 0.4172$ \\
\hline & $650(\mathrm{~mm} / \mathrm{min})$ & $60 \mathrm{~mm}$ & $-0.3833 \pm 0.6636$ & $-0.5929 \pm 0.5957$ \\
\hline & $850(\mathrm{~mm} / \mathrm{min})$ & $60 \mathrm{~mm}$ & $-0.4609 \pm 0.7475$ & $-0.6135 \pm 0.5906$ \\
\hline \multirow[t]{3}{*}{$\theta x y^{2}$} & 2 (rpm) & $90^{\circ}$ & $-0.0428 \pm 0.1380$ & $-0.0610 \pm 0.1387$ \\
\hline & 4 (rpm) & $90^{\circ}$ & $-0.0595 \pm 0.2191$ & $-0.0567 \pm 0.2069$ \\
\hline & 6 (rpm) & $90^{\circ}$ & $-0.0456 \pm 0.3611$ & $0.0296 \pm 0.3381$ \\
\hline \multirow[t]{3}{*}{$\theta x z^{2}$} & 2 (rpm) & $90^{\circ}$ & $-0.0312 \pm 0.1112$ & $-0.0220 \pm 0.0982$ \\
\hline & 4 (rpm) & $90^{\circ}$ & $-0.0715 \pm 0.1134$ & $-0.0801 \pm 0.1442$ \\
\hline & 6 (rpm) & $90^{\circ}$ & $-0.0921 \pm 0.1654$ & $-0.0780 \pm 0.1504$ \\
\hline
\end{tabular}

${ }^{1}$ Means were calculated with 30 repetitions.

${ }^{2}$ Means were calculated with 26 repetitions (4 outliers excluded from analysis).

${ }^{3}$ Movement of the instrument from point a to point $b$, in all the working space.

${ }^{4}$ Movement of the instrument from point $a$ to point $b$ to point $a$, in all the working space.

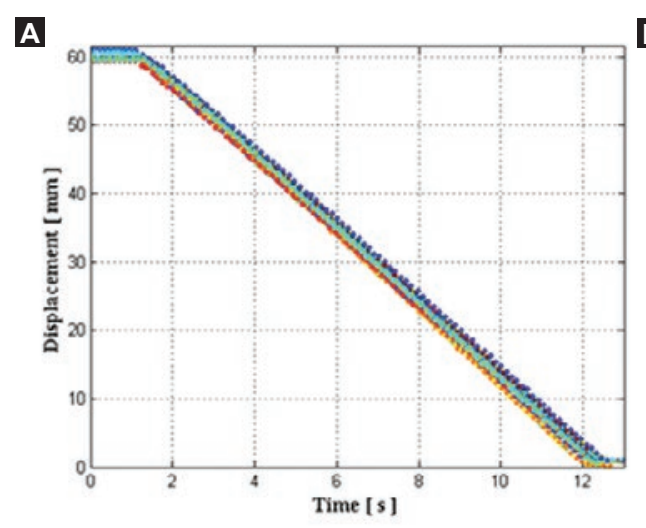

B
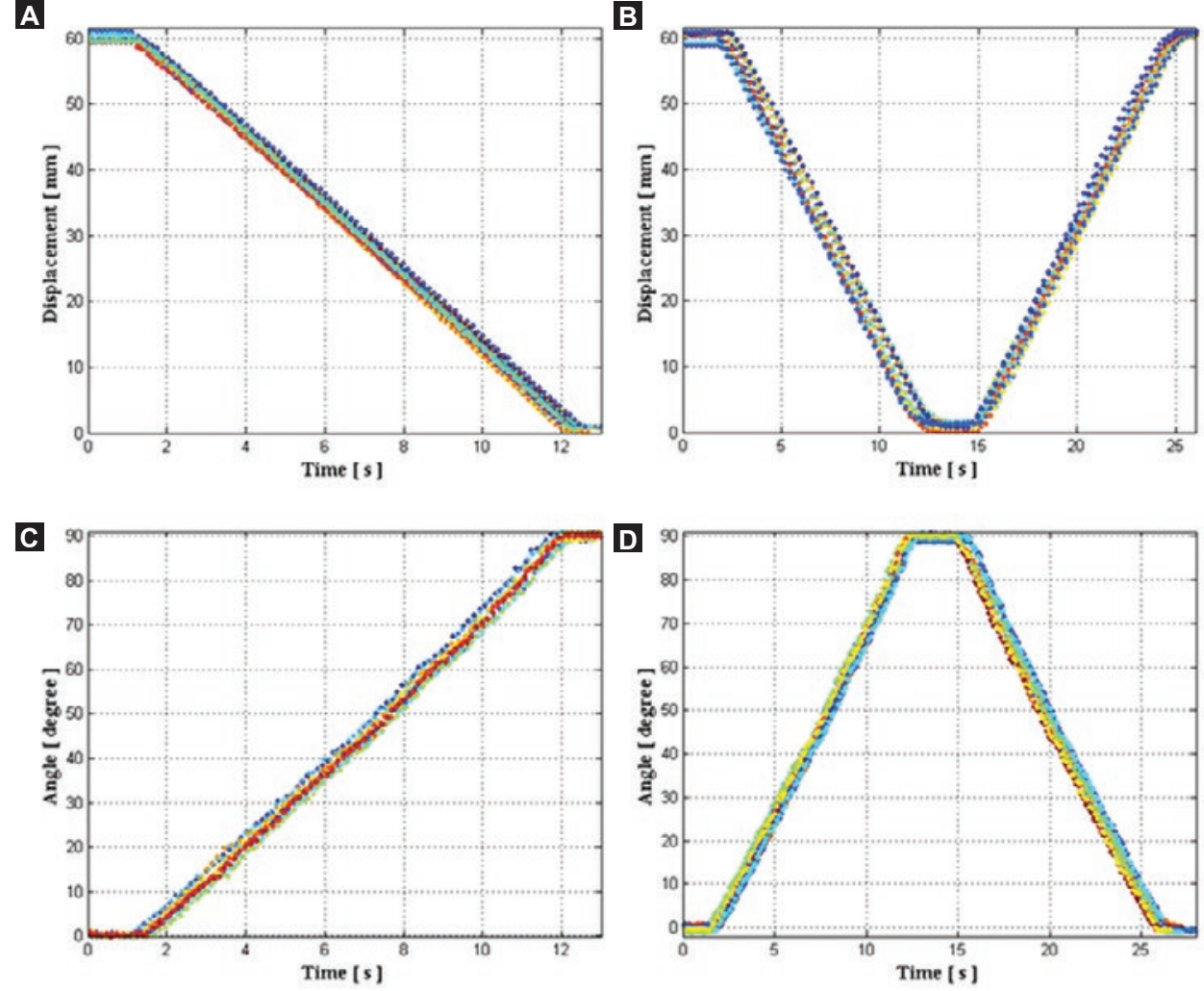

Figure 6. Examples of results of the tests. The movements (a-b) $A$ and $(a-b-a) B$ were performed at a speed of $650 \mathrm{~mm} / \mathrm{min}$, repeated 30 times. The movements $(a-b) C$ and $(a-b-a) D$ were performed with the instruments placed at $45^{\circ}$ at a speed of 4 rpm, repeated 26 times. 
cameras to track the movement of the instruments with precision, reliability, and repeatability. The cameras disposition allows complete visualization of the training setting, regardless of its configuration, and to register instrument movements with high linearity inside the workspace. The system presented does not restrict the natural movement of the instrument necessary to achieve the learning objectives of the surgeons because it does not need sensors or mechanical joints associated with the instruments or the trocars. Furthermore, this tracking system is easy to reproduce due to the use of algorithms well-known in computer vision literature and with the reduced computational cost of image processing, using only two inexpensive webcams.

Color-based segmentation showed its robustness under different lighting conditions such as the lighting environment in which we did the experimental tests. The color code used for the optical marker in green was suitable for the detection of the instrument during the tests. Moreover, it also opens up the possibility of detecting and differentiating more than two instruments simultaneously using markers with different colors. The noise filter, developed with the erosion and dilation morphological operators, avoids the improper instrument detection. The software of instrument detection allows partial occlusion of the optical marker without suffering considerable loss of precision of the color marker; however, in the future, we will work toward total occlusion, performing experiments in more realistic scenarios involving the superposition of the instruments inherent in the manipulation of objects during the training tasks.

The calibration of the cameras system demonstrated the desirable accuracy and precision in obtaining the position of the tip of the instrument in the real world scenario. In particular, analysis of the shape and vanishing point of the surgical instruments within the image used in other video tracking systems was not necessary, thus avoiding detection errors due to shifting illumination conditions inside the simulator or training platforms. Our tracking system only needs a set of benchmarks taken from the workspace of the cameras system; this characteristic makes it easy to adapt to other training platforms and setups. Although our results indicate that calibration of the system should be performed only once, if the orthogonal distance from the cameras is changed or modified, the cameras system must be recalibrated according to the new workspace obtained.

According to the results (Table 2), the smallest movement that the orthogonal cameras system can recognize inside the workspace is below $0.15 \mathrm{~mm}$ in any of the 3DOF. The system presented linearity and repeatability in the three axes $(x, y$, and $z$ ) with errors $<0.62 \%$ which indicates a high precision within the $1694 \mathrm{~cm}^{3}$ of workspace obtained. During testing, the maximum error was found in the $3^{\text {rd }}$ degree of freedom (forward-backward), during the movement test ( $a-b-a)$ at the highest speed. We believe that a possible reason for these outcomes might be due to two factors: (1) the image correction applied to both images being insufficient to reduce the distortion of the cameras and (2) the 6 control points, which were taken in the working space for calibration of the orthogonal cameras system, were not the best set. Considering these, further studies will be carried out to improve the calibration of the images as well as the selection of the best set of benchmarks for an optimal estimation of the instruments position with more accurate results; nevertheless, it is considered that an accuracy of about 2-3 $\mathrm{mm}$ is enough for the analysis of the movements of instruments and the evaluation of performance of the surgeons and trainees ${ }^{25}$.

For the angular movement of the instrument, the minimum recording angle that the system can recognize is below $0.6^{\circ}(0.01 \mathrm{rad})$ with a measurement error of $<0.1 \%$. The maximum error measured during the test $(a-b)$ was for the angle with the $x-z$ plane, $\theta_{x z}$ at the highest speed. The basis for these results might reside in the calculation of angles using the second order moments. This method is very dependent on the amount of light entering to the working space of the cameras. Despite this dispersion of the data relative to the standard deviation, the pattern presented similar accuracy and repeatability during angular movements at different speeds.

Finally, our video-based tracking system offers a low-cost alternative to traditional tracking technologies, a non-obstructive solution for capturing the laparoscopic instruments motion and a portable tool for tracking and registering the performance of the surgeons. In addition, the software of orthogonal cameras system stores the motion data of the laparoscopic instruments in separate sections within a simple text file (*.txt) for the analysis of the execution during the training. In the future, we will integrate motion-based metrics for analysis of the performance of surgeons automatically. Furthermore, validation studies using this orthogonal cameras system incorporated into a box trainer will be conducted, involving the participation of laparoscopic surgeons with different levels of experience. 
In conclusion, a system for tracking the movement of laparoscopic instruments by means of a set of orthogonal cameras and video image processing has been described. This video-based tracking system automatically detects the $3 \mathrm{D}$ position of the surgical instruments within the workspace of the cameras. The experimental trials showed that laparoscopic instruments can be accurately tracked by the orthogonal cameras system with high linearity and repeatability. This tracking system allows the free manipulation of laparoscopic instruments without altering the ergonomics of the surgical instruments and the performance of the surgeons. Furthermore, due to its portability and low-cost, the orthogonal cameras system may be easily adaptable to the different models of simulators.

\section{Funding}

None.

\section{Conflicts of interest}

The authors report no conflicts of interest.

\section{Acknowledgments}

The authors would like to thank Jose Rosas-Ortiz and Irwin Rosales-Garcia of Centro de Investigación y de Estudios Avanzados del Instituto Politécnico Nacional (CINVESTAV-IPN), for their technical assistance in the design, manufacture, and testing of this orthogonal video tracking system.

\section{References}

1. Cuschieri A, Buess G, Périssat J, editors. Operative Manual of Endoscopic Surgery. Berlin, Heidelberg: Springer Berlin Heidelberg; 1992.

2. Cuschieri A. Laparoscopic surgery: current status, issues and future developments. Surgeon. 2005;3:125-30, 132-3, 135-8.

3. Ritter EM, Scott DJ. Design of a proficiency-based skills training curriculum for the fundamentals of laparoscopic surgery. Surg Innov. 2007; 14:107-12.

4. Vassiliou MC, Ghitulescu GA, Feldman LS, et al. The MISTELS program to measure technical skill in laparoscopic surgery: evidence for reliability. Surg Endosc. 2006;20:744-7.

5. Peters JH, Fried GM, Swanstrom LL, et al. Development and validation of a comprehensive program of education and assessment of the basic fundamentals of laparoscopic surgery. Surgery. 2004;135:21-7.

6. Adrales GL, Chu UB, Hoskins JD, Witzke DB, Park AE. Development of a valid, cost-effective laparoscopic training program. Am J Surg. 2004; 187:157-63.

7. Aggarwal R, Moorthy K, Darzi A. Laparoscopic skills training and assessment. Br J Surg. 2004;91:1549-58.
8. Miyajima A, Hasegawa M, Takeda T, et al. How do young residents practice laparoscopic surgical skills? Urology. 2010;76:352-6.

9. Martinez AM, Kalach AC, Espinoza DL. Millimetric laparoscopic surgery training on a physical trainer using rats. Surg Endosc. 2008;22:246-9.

10. Martinez AM, Espinoza DL. Novel laparoscopic home trainer. Surg Laparosc Endosc Percutan Tech. 2007;17:300-2.

11. Botden SM, Buzink SN, Schijven MP, Jakimowicz JJ. ProMIS augmented reality training of laparoscopic procedures face validity. Simul Healthc. 2008;3:97-102.

12. Maciel A, Liu Y, Ahn W, Singh TP, Dunnican W, De S. Development of the VBLaST ${ }^{\text {TM}}$ : a virtual basic laparoscopic skill trainer. Int J Med Robot Comput Assist Surg. 2008;4:131-8.

13. Pellen MG, Horgan LF, Barton JR, Attwood SE. Construct validity of the proMIS laparoscopic simulator. Surg Endosc. 2009;23:130-9.

14. Van Sickle KR, McClusky DA $3^{\text {rd }}$, Gallagher AG, Smith CD. Construct validation of the proMIS simulator using a novel laparoscopic suturing task. Surg Endosc. 2005;19:1227-31.

15. Broe D, Ridgway PF, Johnson S, Tierney S, Conlon KC. Construct validation of a novel hybrid surgical simulator. Surg Endosc. 2006;20:900-4.

16. Botden SM, Jakimowicz JJ. What is going on in augmented reality simulation in laparoscopic surgery? Surg Endosc. 2009;23:1693-700.

17. Hiemstra E, Terveer EM, Chmarra MK, Dankelman J, Jansen FW. Virtual reality in laparoscopic skills training: is haptic feedback replaceable? Minim Invasive Ther Allied Technol. 2011;20:179-84.

18. Minor A, Lorias D, Ortiz S, Escamirosa F. Intelligent mechatronic system for automatically evaluating the training of the laparoscopic surgeon. In: Naik G, editor. Intelligent Mechatronics. London:InTech; 2011. p. 219-28.

19. Sokollik C, Gross J, Buess G. New model for skills assessment and training progress in minimally invasive surgery. Surg Endosc. 2004; 18:495-500.

20. Chmarra MK, Bakker NH, Grimbergen CA, Dankelman J. TrEndo, a device for tracking minimally invasive surgical instruments in training setups. Sensors Actuators Phys. 2006;126:328-34.

21. Munz Y, Moorthy K, Dosis A, et al. The benefits of stereoscopic vision in robotic-assisted performance on bench models. Surg Endosc. 2004; 18:611-6.

22. Wei GQ, Arbter K, Hirzinger G. Automatic Tracking of Laparoscopic Instruments by Color Coding. Berlin, Heidelberg: Springer; 1997. p. 357-66.

23. Voros S, Haber GP, Menudet JF, Long JA, Cinquin P. ViKY robotic scope holder: initial clinical experience and preliminary results using instrument tracking. IEEE/ASME Trans Mechatronics. 2010;15:879-86.

24. Voros S, Long JA, Cinquin P. Automatic detection of instruments in laparoscopic images: a first step towards high-level command of robotic endoscopic holders. Int J Rob Res. 2007;26:1173-90.

25. Cano AM, Lamata P, Gayá F, Gómez EJ. New Methods for Video-Based Tracking of Laparoscopic Tools. Berlin, Heidelberg: In Springer; 2006. p. $142-9$.

26. Oropesa I, Sánchez-González P, Chmarra MK, et al. EVA: laparoscopic instrument tracking based on endoscopic video analysis for psychomotor skills assessment. Surg Endosc. 2013;27:1029-39.

27. Allen BF, Kasper F, Nataneli G, Dutson E, Faloutsos P. Visual tracking of laparoscopic instruments in standard training environments. Stud Health Technol Inform. 2011;163:11-7.

28. Brown DC. Close-range camera calibration. Photogramm Eng. 1971; 37:855-66.

29. Zhang Z. A flexible new technique for camera calibration. IEEE Trans Pattern Anal Mach Intell. 2000;22:1330-4.

30. Prokop RJ, Reeves AP. A survey of moment-based techniques for unoccluded object representation and recognition. CVGIP Graph Model Image Process. 1992;54:438-60.

31. van den Boomgaard R, van Balen R. Methods for fast morphological image transforms using bitmapped binary images. CVGIP Graph Model Image Process. 1992;54:252-8.

32. Hartley RI, Sturm P. Triangulation. Comput Vis Image Underst. 1997; 68:146-57.

33. Hartley R, Gupta R, Chang T. Stereo from uncalibrated cameras. In: Proceedings 1992 IEEE Computer Society Conference on Computer Vision and Pattern Recognition. IEEE Comput. Soc. Press. p. 761-4.

34. Ulises $P$, Sohyung $C$, Shihab A. Volumetric calibration of stereo camera in visual servo based robot control. Int J Adv Robot Syst. 2009;6:5.

35. Osborne JW, Overbay A. The power of outliers (and why researchers should always check for them). Res Eval. 2004;9:1-12. 